\title{
Choosing degree among engineering students; Influence on the success
}

\author{
M. Preciado*, M. Rojo*, I. Moreno**, M. Solaguren-Beascoa*, H. Gonzalo* \\ *Departamento de Ingeniería Civil, Universidad de Burgos. Escuela Politécnica Superior, Calle \\ Villadiego, s/n. 09001 Burgos \\ ** Departamento de Ingeniería Electromecánica. Universidad de Burgos. EscuelaPolitécnica Superior, \\ Avda. Cantabria, s/n, 09006 Burgos
}

\begin{abstract}
The success rate of a university should be calculated taking into account, in addition to students who complete their studies, if they do it with the feeling that the choice of the grade has not been wrong. In this paper, the factors that can influence the feelings error / success of students have been investigated. Three groups were surveyed: high school, first year and final year. It is shown how their expectations and perceptions evolve. Good information appears as an important factor, not only in terms of the studies themselves but it has appeared the need for this information to provide a realistic idea of future employment. The vocation that has been called secondary corresponds to the predilection for a particular branch of engineering and, as expected, also plays a very important role. All students surveyed were engineers, but they pointed, as a reason for feeling wrong, not being in the branch that they liked. The motivational aspects of everyday life in college influence the commitment and performance of students, so they must be analyzed and action should be undertaken to improve the deficiencies identified.
\end{abstract}

Keywords: Vocation; Engineering; Information

\section{Introduction}

The assumption that the vast majority of pupils in the Polythecnic have a vocation which we call primary vocation and this is to be engineers is not enough. The question is whether, what could be called secondary vocation, which is a clear preference for one of the branches of engineering, plays a fundamental role or not in the future success and how students are able to identify the secondary vocation. In fact, in this study, all of the students had choices in the engineering field but what they called their "first choice” (specific branch in engineering) was their supposed real vocation.

The student perceptions change and the study of these changes over the years during which they are studying is fundamental. Develop an identity as an engineer along their studies serves, as Dick and Duffy (2009) stated, as stabilizers in turbulent and dynamic instructional and professional environments. There are two types of changes: professionals (how they analyze their professional future as this is approaching) and social (how they perceive the university and its integration within it). The latter has been proved to be vital as Chen et al. (2008) and Lee et al. (2006) studied, in the sense that it allows us to empower and strengthen aspiring and future engineering professionals to pursue, succeed and find fulfillment in engineering.

Decrease abandonment would be a key objective, but when a student does not leave and finish the degree convinced that he/she was wrong, the university should not be counted it as achievement. The choice of grade will be made when the student has little or no contact with the University. If people is involved in one or another way to the decision it would be important to know if any of those people is an engineer and if somehow represented the model of engineer that these students wanted to be, as it was pointed out by Adams et al. (2011). Also Lichtenstein et al. (2009) studies were made during four years on the changes in students, and they found the strong influence of isolated experiences and contacts with someone who advised them. Jofre and Joanfra 
(2010) also point out that in developed countries, the number of students-minded engineer has a downward trend. Governments are promoting plans to increase it because it is expected to increase labor market for them. The key is to create a clear, positive and realistic view of the role of engineering in society. The good news, according Tansley et al. (2007) are that decisions of students are malleable and engineering can be marketed to engineering students.

Dropouts are more common in the first year and it is necessary to look after this point. Contrary to intuition and according Besterfield-Sacre et al. (1997), many students leave college normally have a good academic performance. In this regard there have been important implantations like the tutorial or mentoring program at which Meyers et al. (2012) referred to, but it would be also necessary to know if these students were wrong in their choice or they simply lost their motivation due to other factors.

After the first year it should be analyzed what we have defined as success through three key points: vocation, commitment and motivation. These last two have been widely developed in the literature by authors like Ohland et al (2008) and Brown et al (2014) respectively. The first reason, ie change in secondary vocation, that a student can suffer because "this is not what he/she expected" has not been treated in the literature too deeply and it is delved in this work. If part of the lack of motivation and commitment is due to the "wrong" choice of the engineering branch (lack of information, misguided advice, changing the social landscape ...), and according to Walden and Foor (2008), it would be essential an easy bureaucracy to encourage students to redirect their academic life.

The goal of this study is to research the influence of the chosen branch on the success feeling of the students. The paper is organized in a first part that explains the questionnaire, a second part with the results and finally the analysis and conclusions based on the results.

\section{Methods}

Some drafts were submitted for the evaluation of the students. The questionnaire was complete though short (one sheet), answers were rated from 1 to 5 and some spaces were available for open answers. Three types of polls were elaborated: $2^{\circ}$ Bachiller (last year before University), $1^{\circ}$ Year and Last years.

Table 1. Blocks of the questionnaires for the students

\begin{tabular}{|c|c|c|}
\hline & Future engineers & Actual students \\
\hline \multirow{2}{*}{ Block 1} & \multicolumn{2}{|c|}{ Sex, age, provenance } \\
\hline & \multicolumn{2}{|c|}{ Actual grade and options in order of preference } \\
\hline Block 2 & \multicolumn{2}{|c|}{ Reasons, influences and difficulties in the choice } \\
\hline \multirow[t]{2}{*}{ Block 3} & What do you expect to find? & What have you found? \\
\hline & \multicolumn{2}{|c|}{ Expectations about professional future } \\
\hline Block 4 & & Feeling success/error \\
\hline
\end{tabular}

\section{Results and Discussion}

While the role of friends and/or acquaintances is the most important, there are more students who believe they were misinformed that well informed. Apparently the two sources of information that report better than the others are press/TV and visit to the University (Figure 1a). 


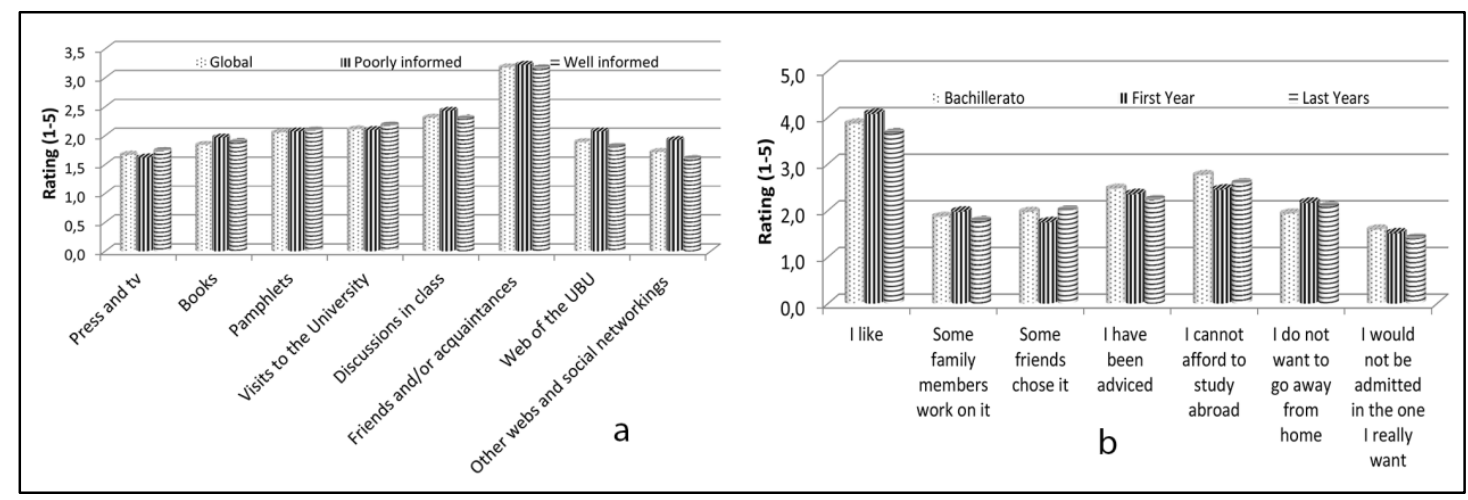

Figure 1. a) Information received by students. b) Relevant reason in the choice of the Grade.

About the reasons that direct the students towards one grade or another (Figure 1b), most students choose to go into engineering because they like (51\%), a factor that we link closely with the vocation.

There is approximately a $65 \%$ of students in the first courses and only $50 \%$ in the last courses that believe that they are not mistaken. This last $50 \%$ is what really should be considered a success rate at universities. In the last years, a $20 \%$ of the students openly believed to have been wrong.

There has been variability in expectations about the everyday life (Figure 2a), which mostly have to do with motivation, it is remarkable the difference that is pointed out by the last years students about questions like: "Much theory and little practical", "New technologies applied to learning" "Teachers explain clearly", "Teachers who encourage," "approve easily." In all of them University come out the loser, so it should be worth analyzing these factors internally. In a book on how to create a good engineer, Goldberg \& Somerville (2015) analyze the great importance of the emotional variables. However, the question "I enjoyed while learning" hasn't fared too badly with a 3.

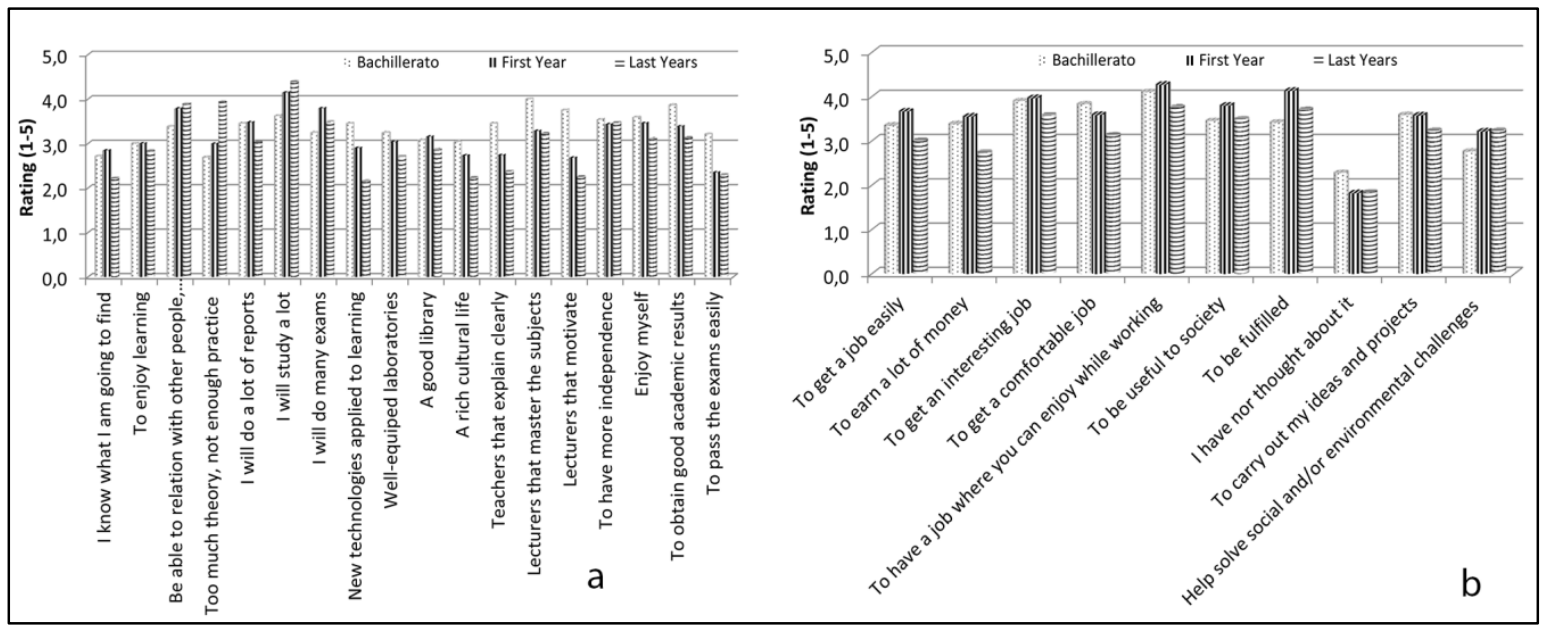

Figure 2. Expectations about a) the everyday life of the university, b) professional future

Regarding their professional future (Figure 2b), there are no questions with large variations, but high values on all major issues (above 3) transmit the "good intentions" of our students and some optimism about their expectations, which is truly commendable in an economic-financial environment such as the one that we have gone through.

Among the analyzed models, it was studied first the influence of the various sources of information used by students to determine whether they have really helped in their 
choice of degree or not. Thus, in the first model, the dependent variable is the feeling of misinformation and the independent variables the sources of information rated from 1 to 5 .

According to this model, the most reliable sources of information, from the viewpoint of, are the press releases and TV and visits to the University. This does not mean they are the best from an objective point of view, but those who feel well informed designated them as accurate. By contrast, the consultation of books, pamphlets, web pages and talks in schools does not appear to have a significant effect on decisionmaking capabilities of students.

Furthermore, the influence of various parameters on the overall sense of success or failure in the choice of degree has been also modeled. In this sense, global models, valid for the average student have been calibrated and specific models with systematic variations that can have students. The variables considered in this stratification are introduced as dummy variables, and were: gender ( 0 male and 1 female) and the year of the student ( 0 in the first year and 1 in final year). In both cases, the dependent variable is the feeling of a wrong choice, all the variables varying from 1 to 5 .

Table 2. Models of failure in the choice.

\begin{tabular}{|c|c|c|c|c|}
\hline & \multicolumn{2}{|l|}{ Global } & \multicolumn{2}{|c|}{$\begin{array}{l}\text { Variations depending } \\
\text { on the type of student }\end{array}$} \\
\hline Variable & Coefficient & Test-t & Coefficient & Test-t \\
\hline Misinformation & 0.7396 & 3.409 & 0.8365 & 3.946 \\
\hline Choice "I like" & 0.2072 & 4.868 & & \\
\hline Choice "I like" (Last years) & & & 0.3634 & 3.764 \\
\hline Choice "I was nort admitted in the one I liked" & 0.6072 & 6.526 & 0.6365 & 6.719 \\
\hline $\begin{array}{l}\text { Choice "I was nort admitted in the one I liked" } \\
\text { (women) }\end{array}$ & & & -0.4389 & -2.006 \\
\hline Choice” I was adviced" & & & 0.2357 & 3.289 \\
\hline Choice "I was adviced” (Las years) & & & -0.3985 & -2.679 \\
\hline Choice "Some Friends chose it" (women) & & & 0.4538 & 2.318 \\
\hline
\end{tabular}

Also, seeing the variables that influence their success or mistake, we can draw interesting conclusions. From the general model it can be stated that success is clearly influenced by the good information and the secondary vocation (since the fact of not being admitted where it is desired is the 2nd cause of failure, and all of them studied engineering). The choice of the degree only because they initially liked (or believing they would like) can also lead to an error. Social-economic reasons are behind this statement.

Analyzing the model with variations depending on the type of respondent, it can be seen that the main reason for failure is still a lack of information. Not to be admitted in the desired grade is again the second cause but this time only for men; women do not consider that serious. However, the choice of the degree just because they liked (before attend it), is considered a wrong way only by final year students, while first year students, perhaps more unconscious, do not perceived it as a bad motive. Relying on the advice of others is regarded negatively by the first year students, but not by the final years, and finally, choosing a degree because the friends enroll is only seen as a bad reason by women while men do not find it a bad reason.

Along with quantitative analysis previously discussed, it is interesting to analyze the responses in the form of opinion or reflection the students surveyed provided. Indeed, certain aspects are difficult to quantify, especially when asked about personal choices, expectations or feelings. 
On the sources of information, the most important point is the lack of knowledge about the actual content of the degree. It is common for high school students to watch a video, receive a brochure or a talk; however, these sources used to be advertised in the same university. This information is often biased, focusing solely on the positive aspects of university life or a brilliant professional future. These perceptions match well with the results of the regression analysis that established as the most influential sources of information press and television (where they can have a more realistic view of careers and the job market for graduates) and visits to the university (where they can hear from those who are studying or at least, watching facilities on site).

Closely related to the information that the students receive when choosing the degree are the high expectations of the new students about what they will encounter at the University. The responses offered when explaining why compliance or not, comments on unmet expectations predominate. The correspondence is almost directly with the data obtained from the evolution of the specific expectations, which highlighted as items that suffered more variation between first and last years: lecturers who can motivate $(-1.5)$, too much theory and not enough practice $(-1,2)$ new technologies for learning (-1.2), teachers who explain clearly (-1.0). It is clear that students who enter to the University has a different vision that the students that are in the last year. The illusion of starting a new project generates expectations that in many cases are cut short by the reality which, in the light of comments, would greatly improve if the inertia of the university system is overcome.

As for the feeling of being wrong, answers are mainly about the relationship between choice and vocation. Most of the comments are from students who believe they have made an excellent choice because "it was what I liked", which agrees with the data of the relatively low sense of being wrong (2.1). Negative responses are performed on all senior students and are related to the wrong choice with the current economic crisis and difficulty observed in finding a job in your field. These statements explain the increased feeling of being wrong from a low value in the first year (1.94) and a higher value the last year (2.45), when thoughts about their professional future become more important as the end of their academic studies is closer.

\section{Conclusions}

The expectations with which a student enters college are relatively high. They expect mostly quality teaching and practice, to enable them to perform a work in the future. Often these expectations are generated by the university system itself. The competition between universities to attract students, makes that the information is too idealized: more than inform, advertise. This is an important factor in the wrong choices of students.

However, even though many of the expectations of high school students do not match the reality, the feeling of being wrong is relatively low. The error in the choice was mainly fixed in the first courses with abandonment or migration to other degrees, driven almost equally by three causes: the failure to meet expectations, the difficulty in passing and lack of vocation. Despite this correction, the feeling of being wrong picks up again closer to the start of working life. This is probably caused by the uncertainty to find work in their field exacerbated by the current economic crisis.

It should be improved the information regarding the characteristics and possibilities for future work that, along with his secondary vocation, are the factors that most influence 
the feeling of success: if the students are well informed, like what the study and know what to expect in their future working life, the success rate will increase.

\section{References}

Adams, R., Evangelou, D., English, L., Dias de Figueiredo, A., Mousoulides, N., Pawley, A. L., Schifellite, C., Stevens, R., Svinicki, M., Martin-Trenor, J., Wilson, D. M. (2011).Multiple perspectives on engaging future engineers, J. of Engineering Education, 100, (1), 48-88.

Besterfield-Sacre, M., Atman C., Shuman L. (1997). Characteristics of freshman engineering students: models for determining student attrition in engineering. Journal of Engineering Education 86(2), 139-50.

Brown, P. R., Rachel, E., McCord, E., Matusovich, H. M., Kajfez, L. (2014). The use of motivation theory in engineering education research: a systematic review of literature, European J. of Engineering Education, DOI: 10.1080/03043797.2014.941339.

Chen, H. L., Lattuca, L. R., Hamilton, E. R. (2008).Conceptualizing engagement: Contribution of faculty to student engagement in engineering. J. of Engineering Education, 97(3), 339-353.

Dick, B. J., \& Duffy, R.D. (2009). Calling and vocacion at work: Definitions and prospects for research and practice. The Counseling Psychologist, 37 (3), 424-450.

Goldberg, D., Somerville, M. (2015). The making of a whole new engineer: four unexpected lessons for engineering educators and education researchers. J. of Engineering Education, 104, (1), 2-6.

Jofré, L., Joanfra Córdoba, L. R. (2010). Attacting student vocations into engineering careers. IEEE EDUCON Education Engineering - The future of global learning engineering education, April 14-16, Madrid, Spain.

Lee, L., Hansen, L. E., Wilson, D. (2006). The impact of affective and relational factors on classroom experience and career outlook among first-year engineering undergraduates, Proceedings of the frontiers in education annual conference, San Diego, CA.

Lichtenstein, G., Loshbaugh H. G., Claar B., Chen, H. L., Jackson, K. Sheppard, S. D. (2009). An engineering major does not an engineer make. J. of engineering education, 227-234.

Meyers, K. L., Silliman, S. E., Gedde N. L., Ohland M. W. (2012).A comparison of engineering students'reflections on their first-year experiences, J. Engineering Education, 169-178.

Ohland M. W., Sheppard S. D., Lichtensteis G., Eris O., Chachra D., Layton R. A. (2008).Persistence, Engagement, and Migration in Engineering Programs. J of Engineering Education, 259-278.

Walden, S. E., Foor, C, (2008). “What's to keep you from dropping out?” student inmigration into and within engineering,J. of engineering education, 191-204. 